\title{
\%
}

\section{AÑOS DE INDEPENDENCIA DE CENTROAMÉRICA: EVOLUCIÓN RECIENTE DE NUESTRAS RELACIONES COMERCIALES Y OPORTUNIDADES PARA LAS EMPRESAS ESPAÑOLAS}

Las relaciones económicas y comerciales entre España y Centroamérica se han intensificado desde la entrada en vigor provisional del pilar comercial del Acuerdo de Asociación entre Centroamérica y la Unión Europea en el año 2013. El comercio bilateral, no obstante, ha crecido sobre todo del lado de las importaciones españolas, de forma que nuestra tasa de cobertura comercial ha pasado de casi el $300 \%$ en 2013 a caer por debajo del $100 \%$ en 2020. Este último año ha sido, de hecho, el primero en el que el saldo comercial se ha tornado deficitario para España. A pesar de ello, la región sigue ofreciendo oportunidades para las empresas europeas, y las empresas españolas se encuentran en una posición privilegiada para aprovecharlas dados los vínculos existentes.

Palabras clave: Costa Rica, El Salvador, Guatemala, Honduras, Nicaragua, Panamá, acuerdo de asociación, comercio.

Clasificación JEL: F14, F53, O54.

\section{Introducción}

El 15 de septiembre de 2021 se cumplirán 200 años de la firma del Acta de Independencia de Centroamérica, por la que la Diputación Provincial de la Provincia de Guatemala proclamó su independencia de España.

Con la firma del Acta de Independencia concluyó un proceso relativamente pacífico, sin grandes batallas, que se había iniciado diez

\footnotetext{
* Secretaría de Estado de Comercio. Ministerio de Industria, Comercio y Turismo.

Versión de julio de 2021.

DOI: https://doi.org/10.32796/bice.2021.3138.7270
}

años antes en San Salvador y que había acumulado varios intentos fallidos de obtener la independencia.

Tras una fugaz unión al Imperio Mexicano que terminó en 1823, Costa Rica, El Salvador, Guatemala, Honduras y Nicaragua formaron las Provincias Unidas del Centro de América —desde 1824, República Federal de Centro América-, que se disolvería a finales de la década de 1830 dando lugar a los cinco Estados que conocemos a día de hoy.

Estos cinco Estados comenzaron a negociar en 2007 en San José, Costa Rica, el Acuerdo de Asociación entre Centroamérica y la $D$ 
Unión Europea (en adelante, el AACUE). EI acercamiento entre Centroamérica y la UE, no obstante, no era nuevo. En la década de 1980, ante la inestabilidad política y la desigualdad económica existente en Centroamérica, se inició un foro de diálogo entre ministros de la Unión Europea y de seis países del istmo centroamericano (los cinco anteriores más Panamá). Este foro, conocido como Proceso de San José, tenía como objetivo promover la paz y la democracia en Centroamérica, y puede considerarse como muy exitoso a nivel político. No obstante, en el seno del Proceso de San José fue haciéndose evidente la necesidad de profundizar en las relaciones entre ambos territorios, de manera que, en la reunión de 2009, que marcaba el 25 aniversario del inicio del proceso, se destaca la necesidad de llegar a una pronta y satisfactoria conclusión de las negociaciones del AACUE.

Las negociaciones del AACUE, a las que se incorporó también Panamá, concluyeron en mayo de 2010, durante la VI Cumbre UE-América Latina y el Caribe, celebrada en Madrid bajo la Presidencia española de la UE. En ese momento, Centroamérica se convirtió en la primera región en alcanzar un Acuerdo de Asociación con la UE, en el que, además de cuestiones comerciales, se incluían también cuestiones relativas al diálogo político y la cooperación.

El éxito de las negociaciones, además de por la voluntad política existente, se puede explicar por factores diferentes en el caso de Centroamérica y de la UE:

- En el caso de los países del istmo centroamericano, por las ventajas comerciales derivadas del AACUE. Anteriormente, la Unión Europea concedía a los países de Centroamérica acceso preferencial al mercado comunitario a través del Sistema de Preferencias Generalizadas (SPG). Sin embargo, este sistema está sujeto a revisiones periódicas, por lo que el AACUE permitía a los seis países consolidar el acceso preferencial de sus productos a la UE.

- En el caso de la UE, por el valor estratégico de Centroamérica en las relaciones comerciales con Asia y Estados Unidos; por la dificultad de avanzar en las negociaciones en el seno de la OMC, que le ha llevado a cerrar acuerdos bilaterales y plurilaterales; por el deseo europeo de apoyar los procesos de integración económica a nivel regional; y, finalmente, por la posibilidad de mejorar el acceso de sus productos al mercado centroamericano, pues hasta entonces el acceso de los productos de la Unión Europea a Centroamérica se regía por la Cláusula de la Nación Más Favorecida de la OMC.

EI AACUE consta de tres pilares: un pilar de diálogo político, un pilar de cooperación y un pilar comercial. Se trata, por tanto, de un acuerdo de competencia mixta, en la medida en que las disposiciones que incluye se refieren, en algunos casos, a competencias que no son exclusivas de la UE. Esto hace que para que se produzca su entrada en vigor sea necesaria la ratificación de todos los Estados miembros, algo que no se ha producido hasta la fecha - está pendiente la ratificación por parte de Bélgica-. El pilar comercial del AACUE, no obstante, afecta únicamente a competencias exclusivas de la UE, por lo que se viene aplicando de forma provisional desde la segunda mitad de 2013.

Desde entonces se ha producido un incremento muy significativo de los intercambios $\triangleright$ 
comerciales entre España y Centroamérica, especialmente en el caso de las exportaciones procedentes desde Centroamérica a nuestro país. Siguen existiendo, por tanto, grandes oportunidades para las empresas españolas en la región, que merece la pena recordar con ocasión de la efeméride de la independencia de Centroamérica.

La primera sección del artículo recoge las principales magnitudes de los países del istmo centroamericano. En la segunda se analiza la evolución de las relaciones comerciales entre Centroamérica y España, especialmente desde la entrada en vigor provisional del pilar comercial del AACUE. A continuación se hace un breve repaso de las relaciones comerciales bilaterales con los seis países centroamericanos que forman parte del AACUE. Para terminar, se identifican algunos de los sectores que ofrecen oportunidades para empresas españolas interesadas en exportar o invertir en la región.

\section{Centroamérica: una región de contrastes}

Los seis Estados centroamericanos parte del AACUE cuentan con una población de 49 millones de habitantes y con un producto interior bruto (PIB) conjunto de más de 200.000 millones de euros, de acuerdo con el Fondo Monetario Internacional (FMI). Estos datos convierten a la región en la sexta más importante de Iberoamérica y el Caribe, con un tamaño similar al de Chile, que tiene, sin embargo, una población mucho menor, de apenas 19 millones de habitantes.

En los próximos cinco años, el FMI espera que la región experimente un crecimiento real promedio del 3,7\% anual, tras haber sufrido una caída del 7,3\% en 2020. La población, de acuerdo con el Banco Mundial, crecerá en ese mismo periodo a una tasa anual promedio del $1,4 \%$, alcanzando los 52,8 millones de habitantes en 2025

Existen, en cualquier caso, diferencias importantes entre países. Guatemala es el país más grande de la región, con un PIB equivalente al $31 \%$ del PIB regional en 2020, y fue también el país menos afectado por la pandemia, con una caída de apenas el $1,5 \%$ del PIB. Panamá, por su parte, experimentó en 2020 una caída del PIB del 18\%, cediendo a Costa Rica el puesto de segunda economía más importante del istmo.

El diferente desempeño económico en 2020 se puede explicar, en buena medida, a partir del análisis de la composición del PIB. Mientras que en Costa Rica y Panamá el peso del sector primario se sitúa en torno al $5 \%$, en Guatemala, Honduras y Nicaragua supera ampliamente el $10 \%$. El peso del sector servicios, mucho más afectado por la pandemia durante 2020, representa en Panamá más del $75 \%$ del PIB.

Si analizamos el PIB per cápita, también encontramos enormes diferencias. Así, el de Costa Rica y Panamá supera los 10.000 euros, mientras que el de Nicaragua apenas alcanza los 1.500 euros. Ello ocurre a pesar de que las tasas de desempleo de Costa Rica y Panamá son las más altas de la región, con un $20 \%$ y $18,5 \%$ respectivamente, más del doble de las de los otros cuatro países centroamericanos.

A nivel macroeconómico, mientras que en Costa Rica y Panamá la deuda pública supera el $60 \%$ del PIB, en Honduras y Nicaragua no alcanza el $50 \%$, y en Guatemala apenas supera el $30 \%$.

Con estos pocos datos podemos identificar dos grandes grupos de países en la región. Por un lado, Costa Rica y Panamá, países de $\triangle$ 
ingresos altos y con problemas típicos de las economías más desarrolladas, como son los elevados niveles de deuda y desempleo. Por otra parte, los países del triángulo norte (Guatemala, El Salvador y Honduras) y Nicaragua, países de ingreso mediano o mediano bajo, con niveles de desempleo y deuda inferiores (con la excepción de El Salvador, cuya deuda roza el $90 \%$ del PIB) y con un mayor peso del sector primario.

\section{Las relaciones comerciales entre Centroamérica y España}

Las relaciones comerciales entre Centroamérica y España se remontan a la llegada de los españoles a la región en el siglo xvi ${ }^{1}$. En ese momento, la economía del Reino de Guatemala, que integraba los territorios actuales de Belice, el estado mexicano de Chiapas, Costa Rica, El Salvador, Guatemala, Honduras, Nicaragua y parte de Panamá, estaba basada en la agricultura, ya que la región no era rica en metales preciosos, con la excepción del territorio correspondiente a lo que hoy en día es Honduras. Así, en paralelo a la agricultura de subsistencia existente con anterioridad a la llegada de los españoles, se fue desarrollando un sistema agropecuario «comercial», integrado por cultivos que requerían una cierta inversión y que en su mayoría eran propiedad de españoles y criollos. Los españoles también introdujeron el ganado mayor, dando lugar al establecimiento de algunas haciendas ganaderas y facilitando el mejor aprovechamiento de los cultivos mediante el uso de carretas tiradas por bueyes, mulas y caballos.

1 Para más detalle sobre las relaciones comerciales históricas entre Centroamérica y España ver Breve historia contemporánea de Guatemala (Luján, 2012).
El sistema agropecuario comercial o de exportación dependió en cada momento de un cultivo principal, que hasta finales del siglo $\mathrm{xVI}$ fue el cacao. En ese momento, el cacao centroamericano fue desplazado por el cacao más competitivo que los españoles producían en Guayaquil, de forma que muchos de los cultivos centroamericanos se reconvirtieron hacia el añil. Otros cultivos de exportación, aunque de menor importancia, fueron el trigo, el azúcar, el tabaco y el algodón.

Si nos centramos en fechas más recientes, al analizar las relaciones comerciales entre Centroamérica y España, el año 2013 marca un punto de inflexión, ya que en el segundo semestre de ese año se produjo la entrada en vigor provisional del pilar comercial del AACUE.

Ello implicó la liberalización inmediata del $69 \%$ de las exportaciones de la Unión Europea a Centroamérica, y la eliminación progresiva, en un plazo máximo de 15 años, de los aranceles de la práctica totalidad de productos no liberalizados de manera inmediata. Centroamérica, por su parte, salió del SPG, pero logró la liberalización inmediata de sus exportaciones de productos industriales a la Unión Europea, así como concesiones en productos agroalimentarios como azúcar, arroz, vacuno, ron y plátano.

Además de lo anterior, el AACUE incluye compromisos en materia de contratación pública y, en particular, la aplicación de los principios de trato nacional y no discriminación.

Todo ello ha provocado un crecimiento muy importante del comercio bilateral entre Centroamérica y la Unión Europea, del que se ha visto especialmente beneficiada España, cuyas exportaciones de bienes a Centroamérica en 2012 representaban el 16,9\% de las exportaciones totales de la UE-27. Entre 2012 y 2019, las exportaciones españolas de bienes a $\triangleright$ 
Centroamérica crecieron un 34\%, desde 840 millones de euros hasta 1.126 millones de euros. Se trata de un crecimiento superior al experimentado por las exportaciones españolas de bienes totales, que crecieron en ese mismo periodo algo menos del $30 \%$.

En el año 2020, en cambio, las exportaciones españolas de bienes a Centroamérica $D$
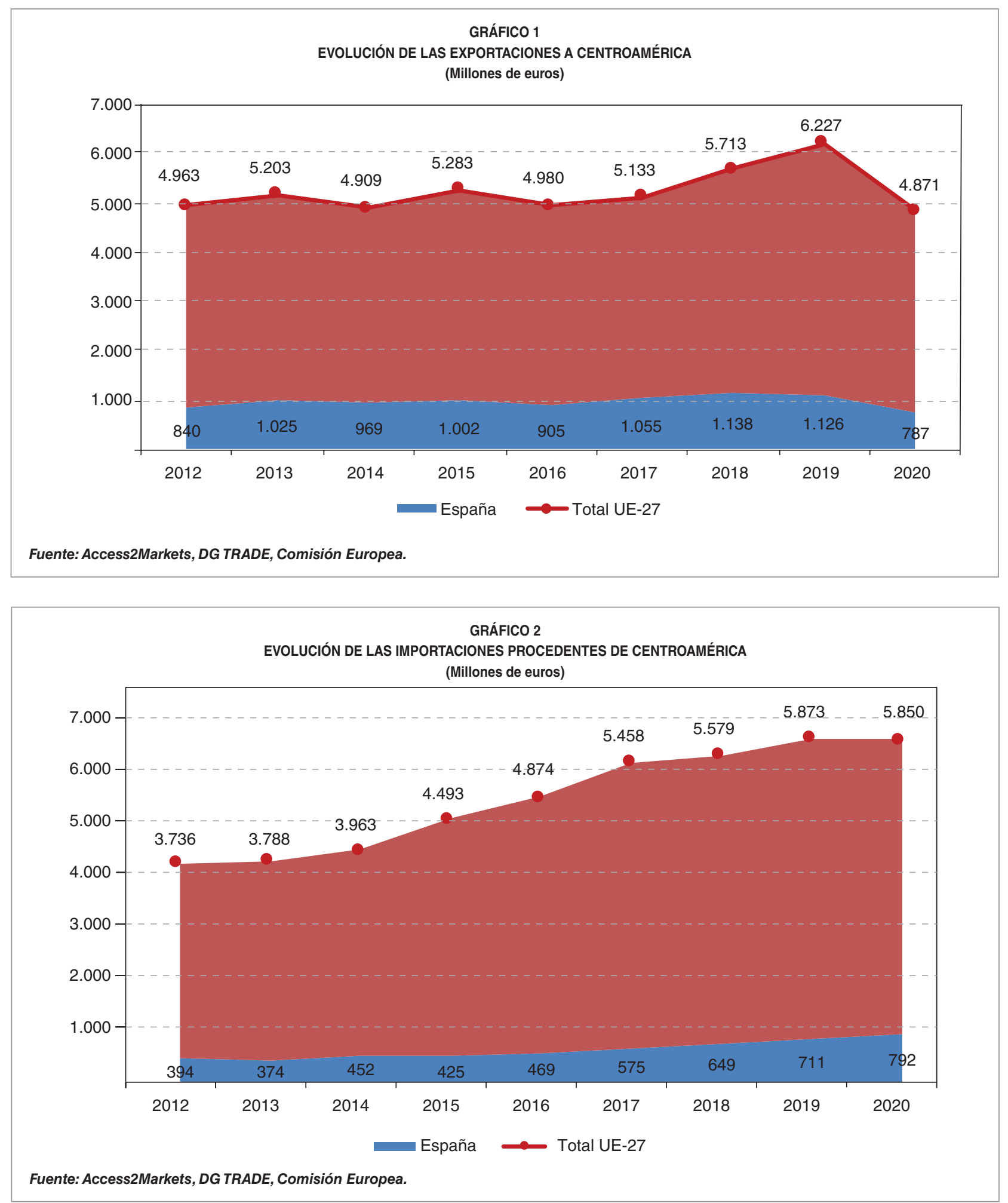
cayeron un 30,1\%, muy por encima de la caída de las exportaciones españolas de bienes totales $(10,2 \%)$ y de fuera de la Unión Europea (13,3\%). El peso de las exportaciones españolas a Centroamérica como porcentaje del total de las exportaciones de la Unión Europea a la región, sin embargo, se mantuvo en niveles similares a los previos a la firma del AACUE, en el 16,2\%, lo que muestra que la magnitud de la caída de las exportaciones a la región en 2020 fue similar en toda la Unión Europea.

Si analizamos las importaciones de bienes centroamericanos por parte de España y de la UE-27, nos encontramos con una situación muy diferente. En el caso de las importaciones españolas, el crecimiento entre 2012 y 2020 fue del $100,7 \%$, con un crecimiento solo en 2020 del $11,3 \%$. En el caso de las importaciones del conjunto de la UE-27, el crecimiento fue algo menor, del $56,6 \%$ entre 2012 y 2020 , manteniéndose la cifra de importaciones en 2020 en niveles similares a los de 2019. Como resultado de lo anterior, el peso de las importaciones españolas de Centroamérica como porcentaje de las importaciones procedentes de Centroamérica de la UE-27, ha crecido desde el $10,6 \%$ en 2012 hasta el 13,5\% en 2020.

Observando los Gráficos 1 y 2, hay algo que llama inmediatamente la atención, y es que mientras que las importaciones españolas procedentes de Centroamérica han experimentado un crecimiento continuado en los últimos años, a una tasa de crecimiento anual compuesto de más del $9 \%$, nuestras exportaciones a la región han mostrado una tendencia $\square$

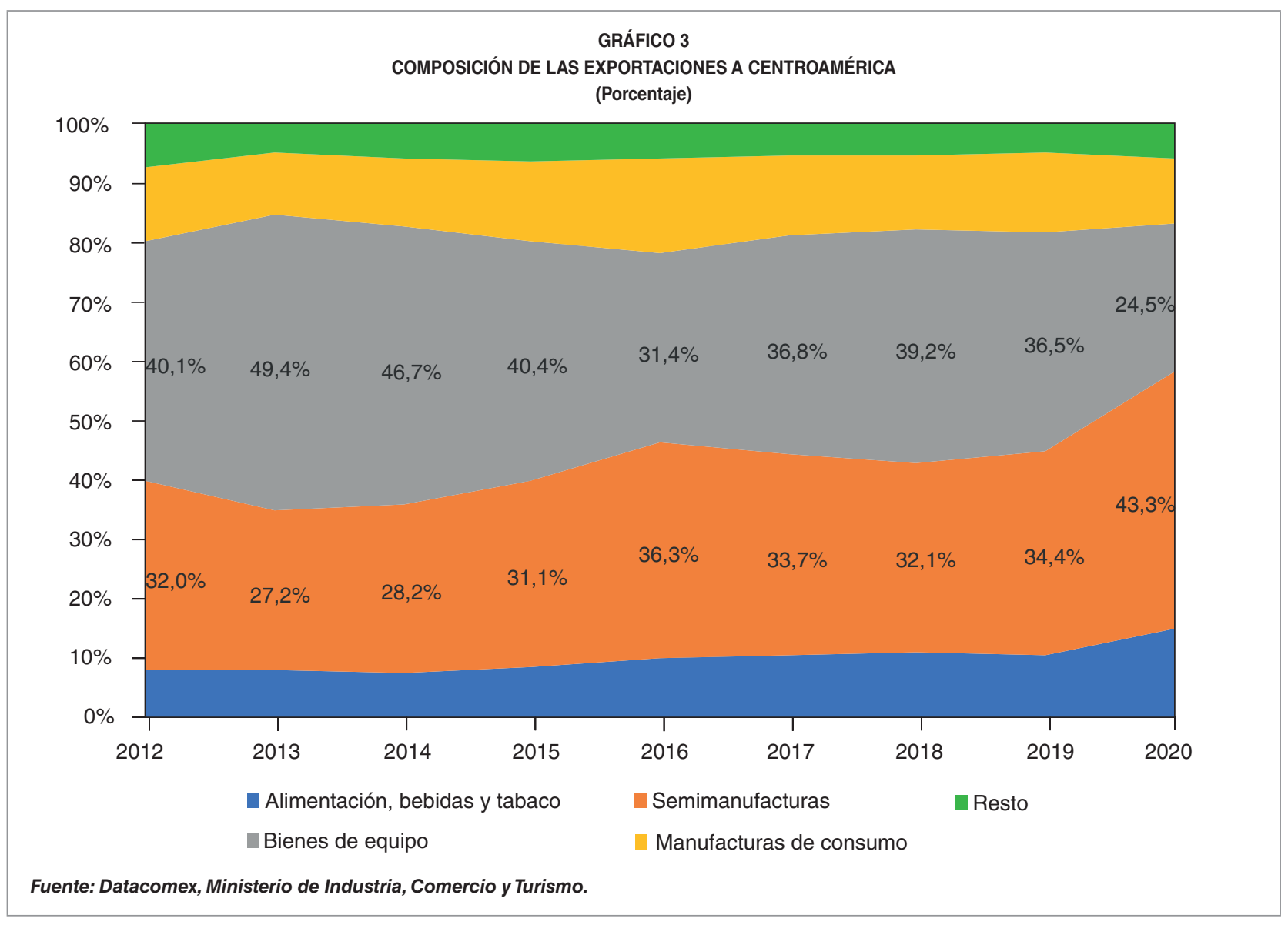


errática, con un crecimiento total incluso negativo si tenemos en cuenta el año 2020.

Desde el punto de vista sectorial, tanto las importaciones como las exportaciones han mostrado una gran estabilidad desde la entrada en vigor del AACUE. La principal partida de exportación española entre 2012 y 2019 fueron los bienes de equipo, seguida de las semimanufacturas, que en 2020 ocuparon la primera posición. Entre las dos han representado todos esos años en torno al $70 \%$ de las exportaciones españolas a Centroamérica. A una distancia considerable les siguen las manufacturas de consumo y los productos alimentarios, cada uno con un peso ligeramente por encima del $10 \%$.

Las importaciones, por su parte, muestran una gran concentración en torno a los productos alimentarios, que en 2012 representaban el
$91 \%$ de nuestras importaciones totales. Su peso se mantuvo estable hasta 2018, cuando representaron el $87 \%$, pero ha caído en los dos últimos años, representando en 2020 el $69 \%$ del total. La otra gran partida de importación española de Centroamérica son las materias primas, aunque su importancia es muy reciente. Frente a un peso promedio en las importaciones entre 2012 y 2018 del 3,1\%, en 2020 representaron un 23,5\%. Esto se explica por las importaciones de concentrado de cobre de la mina Cobre Panamá, que comenzó a operar a mediados de 2019 y que ha provocado un fuerte crecimiento de las importaciones españolas procedentes de ese país.

La alta concentración de las importaciones españolas procedentes de Centroamérica no cuadra con la composición de las $\triangleright$

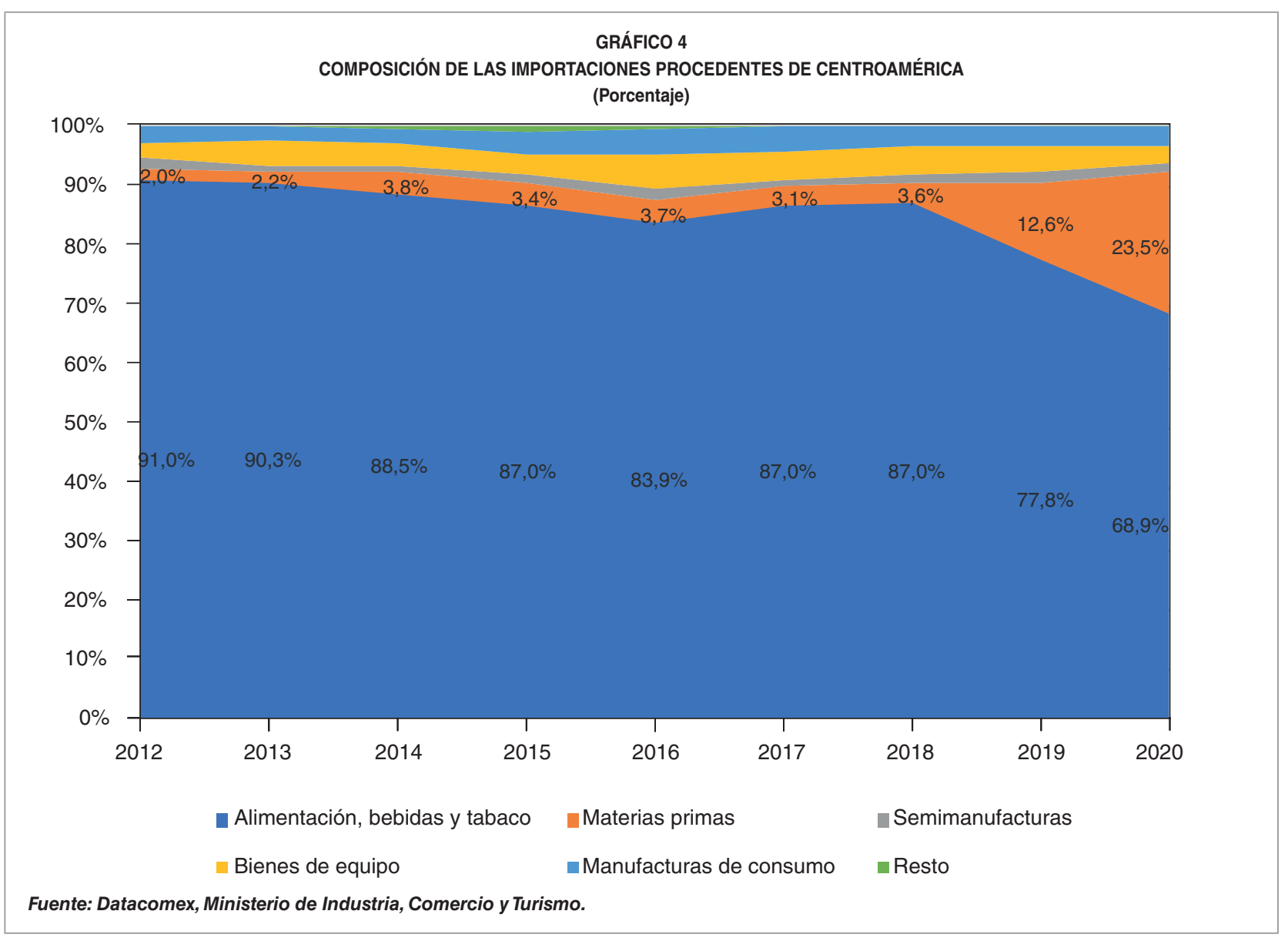


exportaciones totales de los países centroamericanos. En el caso de Guatemala, por ejemplo, los productos alimentarios han representado más del $95 \%$ de las importaciones españolas en los últimos dos años, mientras que, en la composición de las exportaciones totales de Guatemala, el $61 \%$ corresponde a la industria manufacturera, el $29 \%$ a la agricultura y el $9 \%$ a las industrias extractivas. Ello ofrece un gran margen de crecimiento para las exportaciones del país, y algo similar ocurre en los demás países de la región.

Lo que se puede concluir después de este análisis es que, aunque la entrada en vigor provisional del pilar comercial del AACUE ha permitido un gran crecimiento de los intercambios comerciales - superior al crecimiento global de los intercambios comerciales de España con el resto del mundo-, dicho crecimiento se ha producido generalmente a través de una intensificación de los intercambios de aquellos productos que ya se intercambiaban antes de la entrada en vigor provisional del AACUE. No se ha producido, en cambio, una mayor diversificación ni de las exportaciones de bienes españoles ni de nuestras importaciones procedentes de Centroamérica, con la excepción de las importaciones de material de cobre procedente de Panamá, que se explican por el inicio de las operaciones de la mina Cobre $\triangleright$

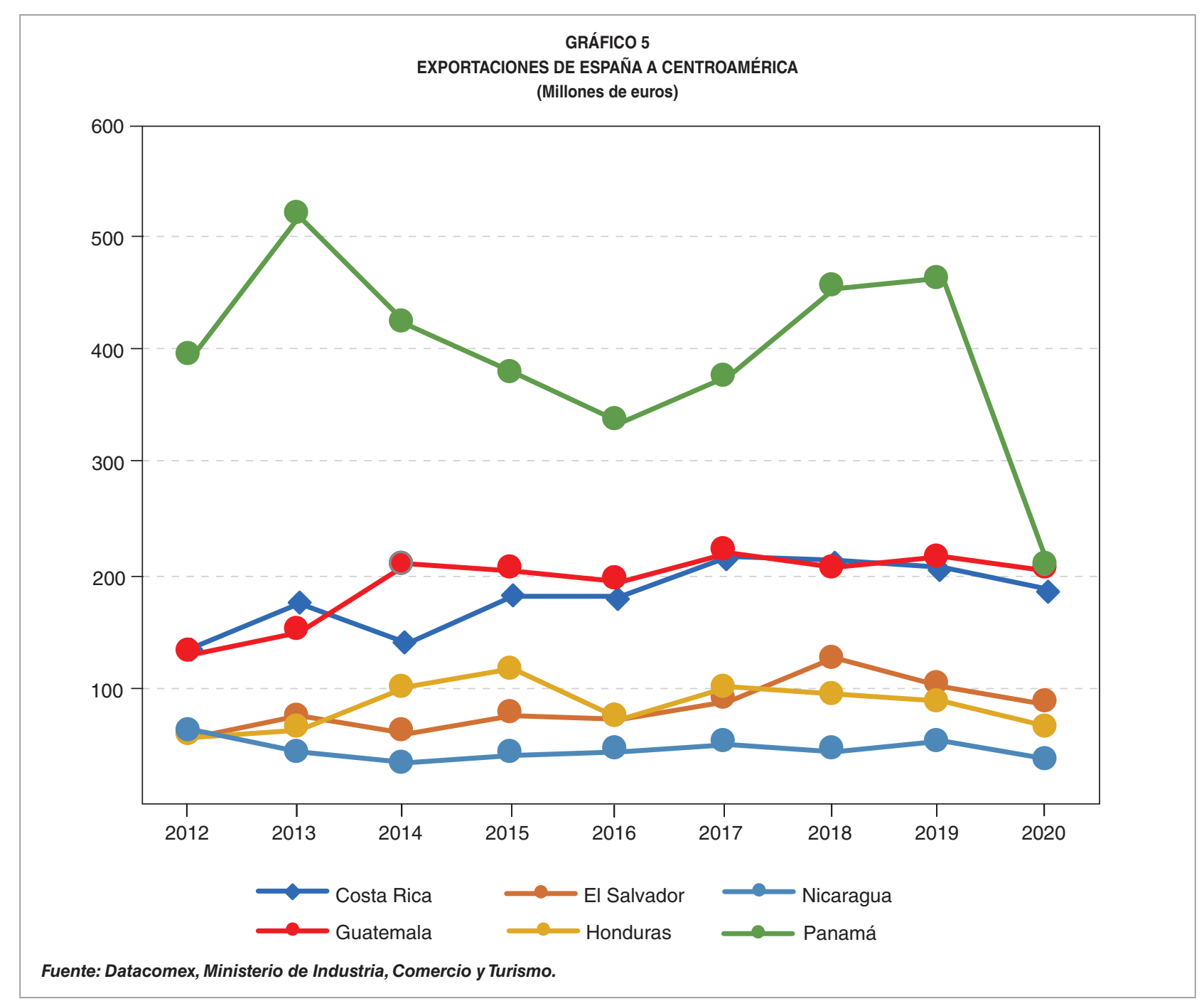


Panamá, y no tanto por las ventajas derivadas del AACUE.

\section{Evolución de las relaciones comerciales por país}

Aunque útil para realizar un repaso general de las relaciones comerciales entre España y Centroamérica, el análisis del apartado anterior esconde diversas tendencias que se pueden apreciar mejor si desagregamos los datos correspondientes a los seis países que forman parte del AACUE. Veamos, por tanto, la contribución de cada uno de esos países a las exportaciones e importaciones españolas.
Lo primero que se observa al realizar esa desagregación es la caída del peso de Panamá en las exportaciones españolas a Centroamérica, que ha pasado del $50 \%$ en el momento de la entrada en vigor del AACUE al $41 \%$ en 2019 y al $27 \%$ en 2020 . El peso de las exportaciones españolas a Guatemala y Costa Rica, en cambio, ha crecido en ese mismo periodo desde el $16 \%$ hasta el $26 \%$ y el $24 \%$, respectivamente. El Salvador, Honduras y Nicaragua fueron destino en 2020 del $11 \%$, $8 \%$ y $5 \%$ de las exportaciones españolas a Centroamérica, respectivamente.

El origen principal de las importaciones españolas de la región, por su parte, sigue siendo Costa Rica, a quien seguía $D$

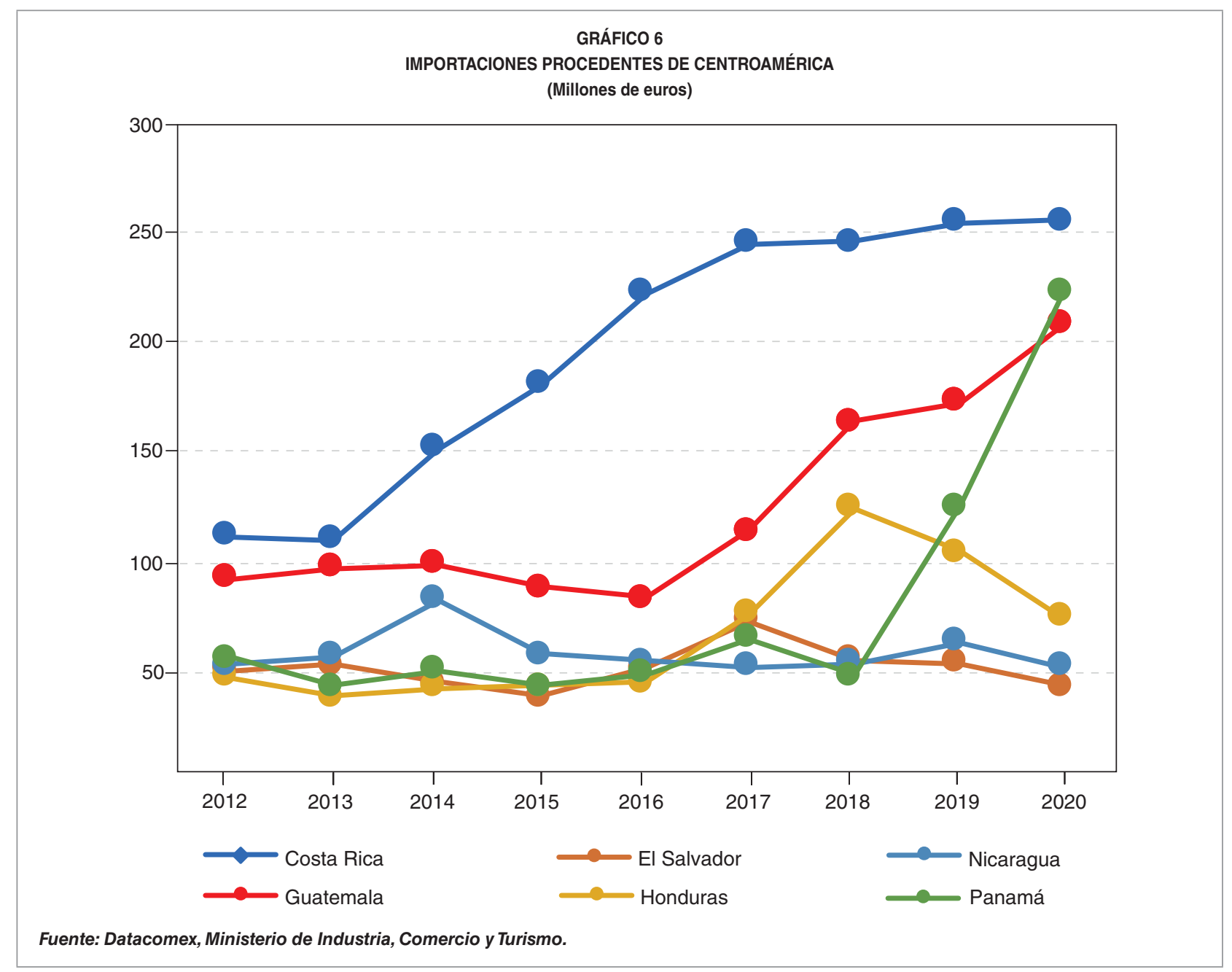




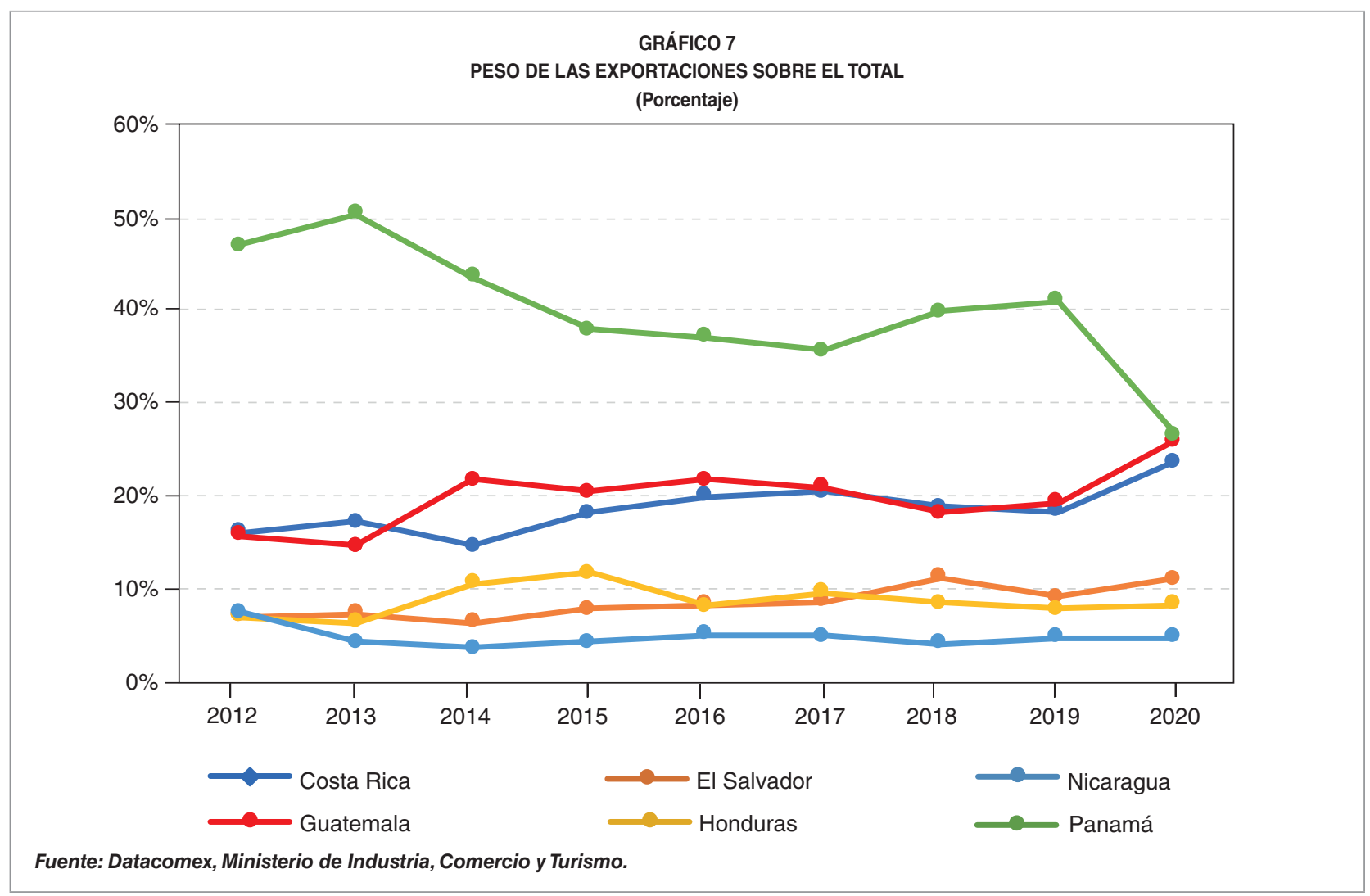

tradicionalmente Guatemala. En 2020, no obstante, el segundo puesto fue ocupado por $\mathrm{Pa}$ namá, que fue origen del $26 \%$ de las importaciones españolas de Centroamérica, frente a un peso promedio entre 2012 y 2019 del $11 \%$. Esto se explica, como veíamos antes, por el gran crecimiento de las importaciones de concentrado de cobre procedente de la mina Cobre Panamá. El peso de las importaciones procedentes de Honduras, Nicaragua y El Salvador se situó por debajo del $10 \%$ en 2020 , siguiendo además una tendencia descendente en los últimos años.

Lo anterior ha provocado una gran caída de la tasa de cobertura comercial de Panamá, que ha pasado de casi el $1.200 \%$ en 2013 al $94 \%$ en 2020. Los demás países de la región, con la excepción de El Salvador, han experimentado una tendencia similar, aunque menos pronunciada. Así, El Salvador ha sido el único país que ha visto aumentar su tasa de cobertura comercial desde la entrada en vigor del AACUE. A nivel agregado, la tasa de cobertura comercial pasó del $255 \%$ en 2013 al $145 \%$ en 2019, y en el año 2020 cayó hasta el $92 \%$.

El pasado año fue, por tanto, el primero de la serie histórica en el que las importaciones procedentes de Centroamérica superaron a las exportaciones españolas a la región. Si analizamos la evolución del saldo de la balanza comercial desde la entrada en vigor del AACUE, vemos que este fue de 623 millones de euros en 2013, y que ya en 2019 había caído cerca del 50\%. En 2020 se acentuó esa tendencia, fundamentalmente por el empeoramiento del saldo de la balanza comercial de España frente a Panamá, lastrado, como veíamos antes, tanto por la caída de las exportaciones a ese país como por el importante aumento de las importaciones procedentes $\square$ 
del mismo. Así, mientras que en 2012 España mantenía superávit comercial frente a los seis países que forman parte del AACUE, en 2020 solo mantenía superávit comercial frente a $\mathrm{El}$ Salvador.

\section{Principales sectores de oportunidad para las empresas españolas}

Como veíamos hace un momento, el AACUE implicó la liberalización de muchos productos de exportación españoles que, hasta ese momento, se regían por la Cláusula de la Nación Más Favorecida de la OMC. Además, el proceso de industrialización de distintos sectores industriales y agrícolas que están experimentando todos los países de la región ofrece a las empresas españolas la posibilidad de exportar productos de cada vez mayor valor agregado.
Todo ello presenta a las empresas españolas distintas oportunidades que vamos a estudiar a continuación.

En primer lugar, existen grandes oportunidades para la exportación de maquinaria textil y para la confección, principal sector de exportación en El Salvador, Guatemala y Honduras, que son grandes proveedores de confección para el mercado estadounidense. La exportación de maquinaria para procesamiento, envasado y empaquetado de alimentos, así como la maquinaria agrícola y la tecnología de riego e invernadero ofrece también oportunidades en todos los países de la región.

Otra necesidad común a todos los países de Centroamérica es la infraestructura, especialmente de transporte, lo que abre la puerta a la exportación de maquinaria para construcción y obras públicas. Existen, además, numerosos proyectos en este ámbito que $D$

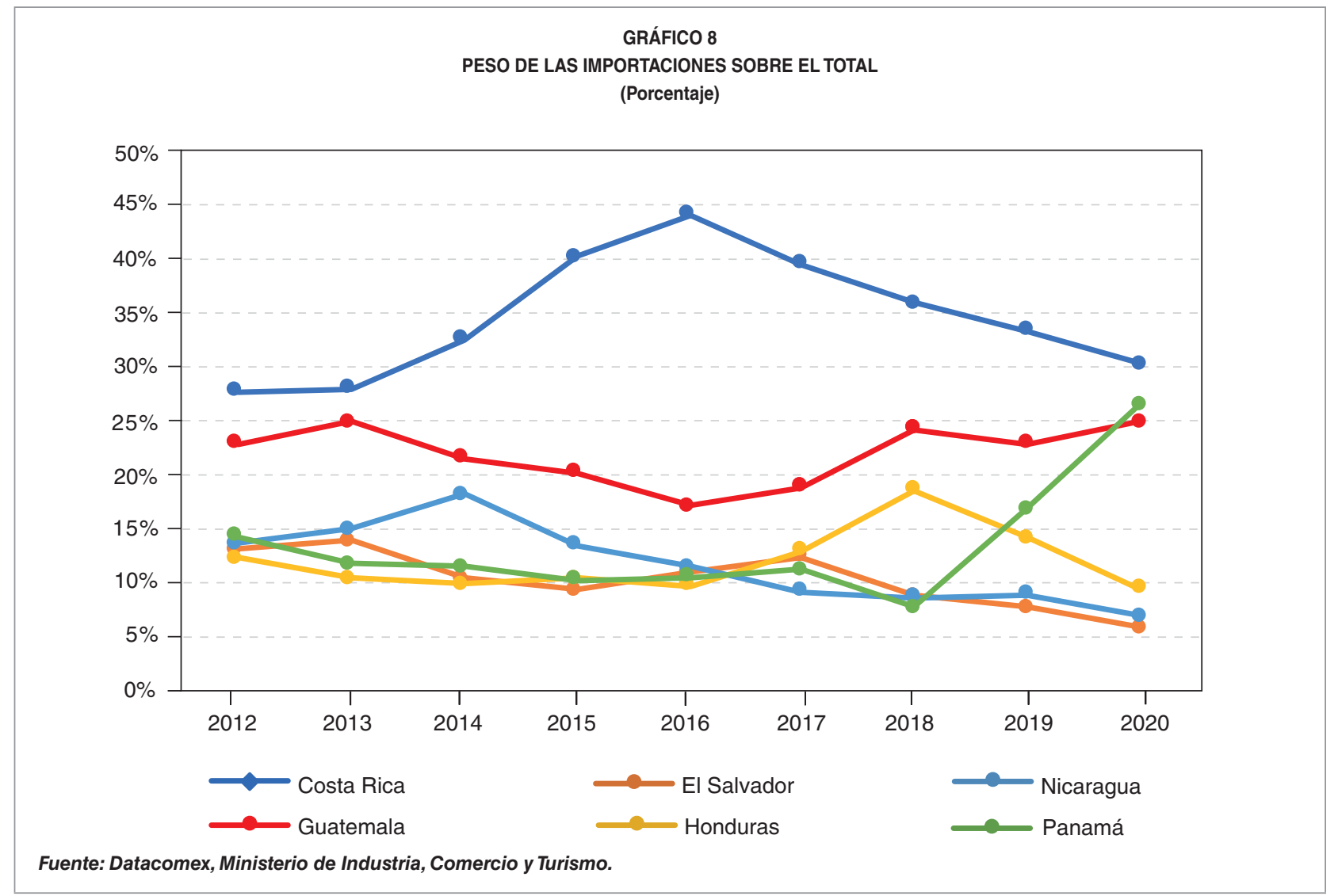


cuentan con financiación de instituciones financieras internacionales, algo que ha sido aprovechado en muchas ocasiones por empresas españolas.

Dichos proyectos ofrecen también oportunidades a empresas de los sectores de ingeniería y consultoría, aunque sus oportunidades no se circunscriben al ámbito de la obra pública. También hay una gran demanda por parte de instituciones internacionales de consultoras especializadas en modernización del Estado, educación, capacitación, apoyo a la justicia y al sector sanitario.

Este último sector, cuyas debilidades en la región han quedado en evidencia a raíz de la pandemia de la COVID-19, es uno de los que cuenta con mayores perspectivas de inversión en el medio plazo, algo a lo que deberán prestar atención las empresas exportadoras de equipamiento hospitalario.
La región centroamericana ofrece también oportunidades en materia de generación de energías renovables, sector en el que España es una potencia a nivel internacional y cuyo desarrollo ha constituido en muchos países de la región una política de estado.

En lo que se refiere a bienes de consumo, todos los países de la región presentan niveles de desigualdad muy elevados. Así, existe un reducido porcentaje de población con elevado poder adquisitivo que demanda productos de calidad, sobre todo alimentos (especialmente aceites y vinos, pero también conservas, quesos y embutidos), cosméticos y confección. A medida que se produzca el desarrollo socioeconómico de la región, la demanda de estos productos irá en aumento.

Para terminar, no podemos olvidar que los países del istmo centroamericano, y muy especialmente Nicaragua y los países del $D$

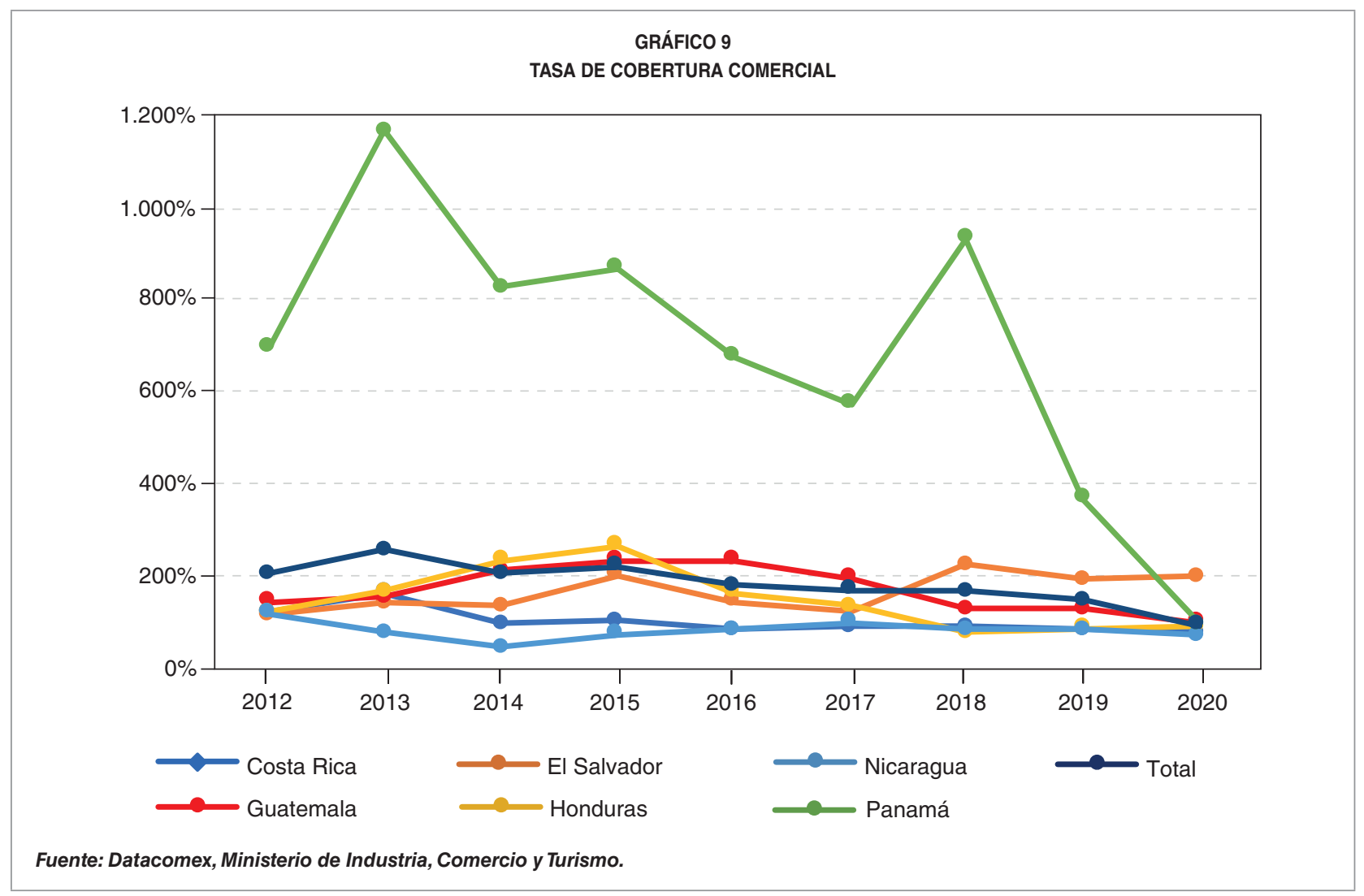




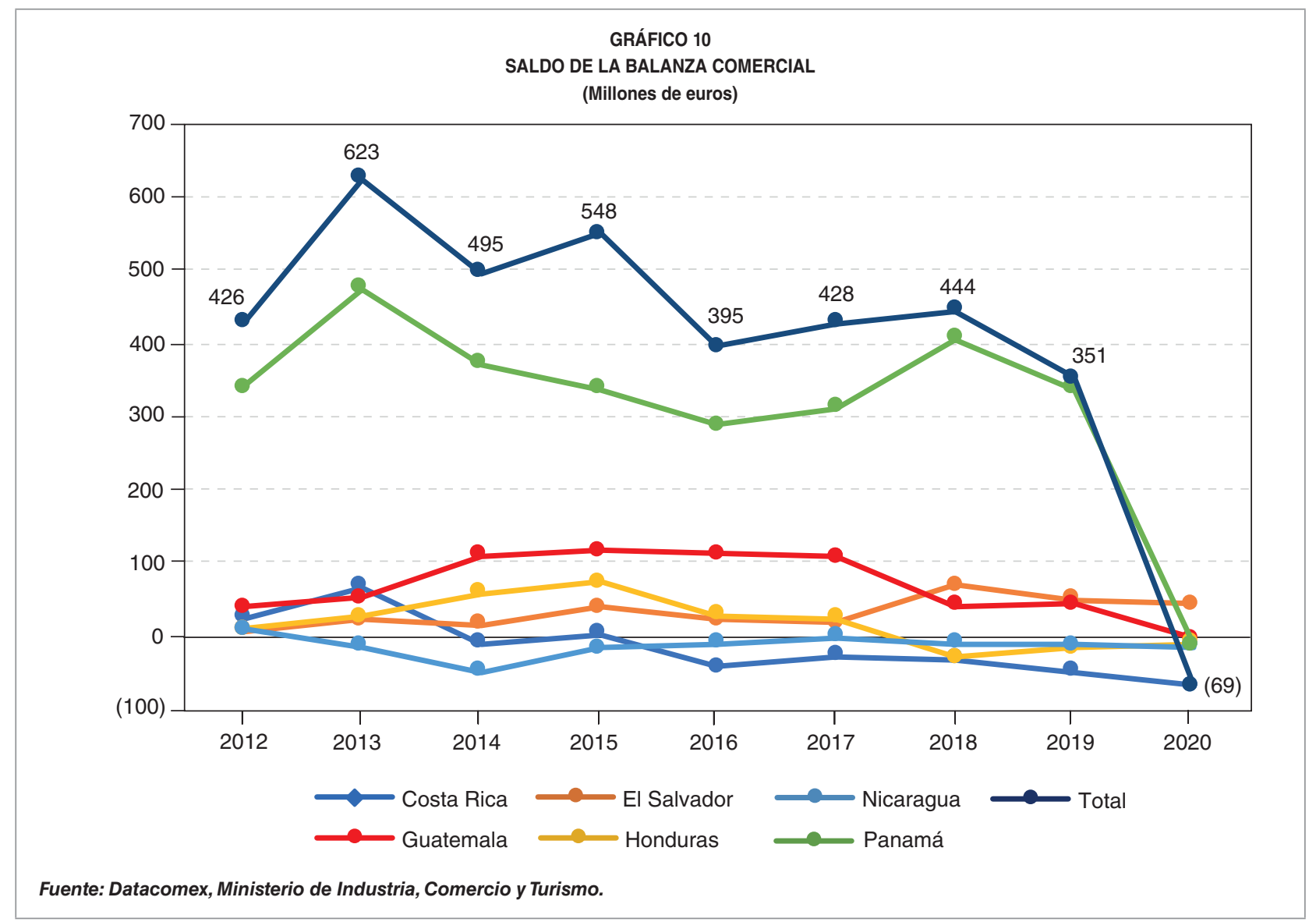

triángulo norte (Guatemala, El Salvador y Honduras), son grandes destinatarios de cooperación bilateral española y de financiación multilateral, que centra gran parte de sus recursos en el sector del agua y saneamiento, lo que ofrece oportunidades a las empresas de equipamiento de este sector, así como a las empresas de depuración de aguas y de tratamiento de residuos.

Respecto a las empresas interesadas en invertir en la región, los seis países de Centroamérica tienen suscritos con España acuerdos para la promoción y protección recíproca de inversiones, lo que aumenta la seguridad jurídica de las inversiones españolas.

Se trata de una región con abundante población en edad de trabajar; con grandes recursos naturales sin explotar; una posición geográfica privilegiada, algo clave dada la actual tendencia hacia el nearshoring de las cadenas de producción; y acuerdos de libre comercio con Estados Unidos, México y la Unión Europea, entre otros.

Todo ello ofrece oportunidades en sectores intensivos en mano de obra, como pueden ser los de manufactura liviana, infraestructuras, BPO (Business Process Outsourcing) y vestuario y textiles. En materia de infraestructura, varios países de la región están tratando de desarrollar proyectos bajo la modalidad de alianzas público privadas.

Dicho todo lo anterior, no podemos dejar de mencionar una gran limitación, que posiblemente explique la todavía limitada presencia de empresas españolas en la región, al menos si la comparamos con otras economías iberoamericanas de tamaño similar. Dicha limitación no es otra que la fragmentación de un mercado, ya de por sí, de tamaño moderado. Esto es así $\square$ 
a pesar de la existencia de un proceso de integración regional, cuyo origen se remonta a la década de los años cincuenta, pero al que le queda todavía mucho por avanzar.

\section{Conclusión}

A modo de conclusión, cabe señalar que, pese al gran potencial todavía existente, las relaciones económicas de España con Centroamérica no dejan de ser las más importantes de cualquier país europeo con la región, algo lógico dados los lazos históricos que nos unen. La entrada en vigor provisional del pilar comercial del AACUE, en el año 2013, ha permitido intensificar esas relaciones, si bien hasta ahora el crecimiento de las relaciones comerciales se ha producido sobre todo del lado de las importaciones españolas. Cabe esperar que, a medida que avance el proceso de integración centroamericana y que los países de la región vayan experimentando un mayor desarrollo socioeconómico, aumenten las oportunidades de exportación para las empresas españolas.

\section{Bibliografía}

Acuerdo por el que se establece una Asociación entre la Unión Europea y sus Estados miembros, por un lado, y Centroamérica, por otro. Diario Oficial de la Unión Europea, n. 346, de 15 de diciembre de 2012, pp. 3 a 2621. https://eur-lex. europa.eu/legal-content/ES/TXT/ PDF/?uri=CELEX:22012A1215(01)\&from=ES

Luján Muñoz, J. (2012). Breve historia contemporánea de Guatemala. Fondo de Cultura Económica.

Reglamento (UE) n. 978/2012 del Parlamento Europeo y del Consejo, de 25 de octubre de 2012, por el que se aplica un sistema de preferencias arancelarias generalizadas y se deroga el Reglamento (CE) no. 732/2008 del Consejo. Diario Oficial de la Unión Europea, n.ํㅜ 303, de 21 de octubre de 2012, pp. 1 a 82. https://www.boe.es/ doue/2012/303/L00001-00082.pdf 